\title{
Evaluation Treatment Planning for Breast Cancer Based on Dose-Response Model
}

\author{
Siti Aisyah ${ }^{1}$, Aditya Prayugo Hariyanto ${ }^{1}$, Endarko ${ }^{1 *}$, Agus Rubiyanto $^{1}$, Nasori ${ }^{1}$, \\ Mohammad Haekal ${ }^{1}$, Andreas Nainggolan ${ }^{2}$ \\ ${ }^{1}$ Laboratory of Medical Physics and Biophysics, Department of Physics, Institut Teknologi \\ Sepuluh Nopember, Kampus ITS Sukolilo - Surabaya 60111, East Java, Indonesia \\ ${ }^{2}$ Cancer Specialty Hospitals MRCCC Siloam Semanggi, 19230, South Jakarta, Indonesia \\ "E-mail: endarko@physics.its.ac.id
}

\begin{abstract}
The delivery of radiation therapy to patients requires prior planning made by medical physicists to achieve radiotherapy goals. Radiotherapy has a plan to eradicate the growth of cancer cells by giving high doses and minimizing the radiation dose to normal tissue. Evaluation of planning is generally done based on dosimetric parameters, such as minimum dose, maximum dose, and means dose obtained from the Dose-Volume Histogram (DVHs) data. Based on the same DVHs, data were evaluate dinterms of biological effects to determine the highest possible toxicity in normal tissue after the tumor had been treated with radiation using the Normal Tissue Complication Probability (NTCP) model. The evaluation was conducted by selecting three DICOM-RT data of post-mastectomy right breast cancer patients who had been prescribed a dose of 50 Gy obtained from the Hospital MRCCC Siloam Semanggi database. All data were processed using opensource software DICOMan ${ }^{\mathrm{TX}}$ to get the DVH and isodose information. Matlab-based CERR software was used to calculate the NTCP model. The results show that the three patients' DVH and isodose treatment planning result in a homogeneous dose distribution result because the PTV area obtains adose limit of $\geq 95 \%$. Moreover, normalt issue still gets adose below the tolerance limit based on the standard from RTOG 1005 and ICRU 83. Analysis of NTCP shows a complication probability below $1 \%$ for each organ, suggesting that any organ which has been irradiated has a low likelihood of complications. Therefore, it can be concluded that the treatment planning which has been made in the three patients using the IMRT technique has achieved the objectives of radiotherapy, which is to minimize toxicity to healthy organs.
\end{abstract}

Keywords: Dose-Volume Histogram, Isodose, Normal Tissue Complication Probability, Radiotherapy.

\section{INTRODUCTION}

Breast cancer is a type of cancer whichoccurs more frequently than other types of cancer in women (Ronckers et al., 2005). Recently, based on data from the American Cancer Association in 2019 in the United States, it has been estimated that breast cancer cases accounted for 268,600 thousand (30\%) cases of new cancer diagnoses and 41,760 thousand $(15 \%)$ cases of death in women. In addition, breast cancer is one of the three most common cancer cases in women after lung and colon rectum cancer (Ronckers et al., 2005; Siegel et al., 2019; Siegel et al., 2019).

Breasts are considered the attribute of femininity and sexuality for women, so if they are lost, they can affect a woman's quality of life (Abebe et al., 2020). Because of this, the treatment of breast cancer requires multidisciplinary methods, such as the combination of surgery and Radiotherapy (RT), drug therapy as an adjuvant treatment, so that the treatment goal is achieved (Supakalin et al., 2018; American Cancer Society, 2021). A study conducted by Zablotska \& Neugut (2003) explains that breast cancer can cause metastases to normal tissues, such as the lung, and trigger the onset of lung carcinoma. Zablotska investigates mastectomy treatment and additional RT and reveals that it causes lung carcinoma to decrease compared to only giving mastectomy treatment alone with the number of cases sequentially 345 and 1.885 (Zablotska \& Neugut, 2003).

Usually, the treatment used is a combination of surgery and radiation therapy. Surgery on breast cancer is divided into two, namely breast conservation therapy or lumpectomy and mastectomy or removing the entire breast and then followed by external radiotherapy using LINAC (American Cancer Society, 2021). The choice between mastectomy and lumpectomy is usually made under the consideration of an oncologist, and 
the right selection will give long-term consequences of treatment (Zablotska \& Neugut, 2003).

Postoperative radiation delivery to breast cancer has been shown to improve patient survival, compared to surgery alone (Abe et al., 2005). Based on a study by the Early Breast Cancer Trialists' Collaborative Group, the mortality rate from breast cancer with postsurgical radiotherapy treatment is $40.3 \%$, compared to that without radiotherapy at $41.4 \%$. This points out that combination treatment with radiotherapy reduces the mortality rate after mastectomy or breast conservation surgery (Early Breast Cancer Trialists' Collaborative Group, 1995).

RT treatment in postoperative breast cancer aims to prevent cancer recurrence in the local area (Harris, 2014). Based on a clinical trial in 2005 by the Early Breast Cancer Trialists Collaborative Group (EBCTCG), RT not only reduces cancer recurrence in the local area, but also inhibits metastasis. However, providing RT care is a challenge for a medical physicist because of the presence of OARs (Organs at Risk) around the breasts, coupled with the motion of the lung and heart. Therefore, the RT treatment planning system has tobe made accurately to meet the target volume to be irradiated for maximum dose and homogeneous dose distribution, while at the same time minimizing radiation in OARs (Pyakuryal et al., 2010).Modern techniques commonly used in the treatment of RT are 3Dimension Conformal Radiotherapy (3DCRT), Intensity-Modulated Radiation Therapy (IMRT), and Image-Guided Radiation Therapy (IGRT) (Pyakuryal et al., 2010). Based on RTOG 1005, the IMRT technique leads toan increased dose distribution in the breast, where as in OARs, such as the lung and heart,it generates low doses and indicates low toxicity (Chui et al., 2002; Freedman et al., 2006; Rudra et al., 2014; Vicini et al., 2002). In addition, (Harsolia et al., 2007) also report that the IMRT technique reduces the significant presence of acute dermatitis, edema, and hyperpigmentation, compared to conventional wedge-based radiation techniques.

Traditionally, the RT plan's qualityis based on the dose limit value in OARs and the mean doseof each (Region of Interest) ROI when referring to the RTOG. To that end, ICRU reports 83 guidelines. The RT plan will be more effective if it is evaluated in terms of physical dosimetry and biological effects. Because the endpoint of radiotherapy is not the dose distribution, it is essential to investigate how likely it is to control the tumor in the local area. This is known as the Tumor Control Probability (TCP) and Normal Tissue Complications Probability (NTCP) (Nahum, 1996).

Evaluation of this biological effect aims to maximize TCP and minimize the NTCP (Nahum, 1996). These two radiobiological parameters show the toxicity which affects normal tissue after radiation. Tapping into the evaluation treatment planning on breast cancer, this study will evaluate the IMRT treatment planning system in post-mastectomy breast cancer cases based on biological response using radiobiological models, namely TCP and NTCP. The evaluation results are projected to investigate how the two parameters affect the patient's treatment planning.

\section{METHODS}

\section{Patient Data}

Three Digital Imaging and Communications in Medicine Radiotherapy (DICOM-RT) datasets were selected from the MRCCC Siloam Semanggi Hospital database, labeled as ID1, ID2, and ID3. The selection process was based on mastectomy breast cancer (breast that has been removed). The tumor cells were located in the right breast. The prescription dose was 50 Gy with a daily dose of 2 Gy, and the treatment planning system employed IMRT techniques. The treatment planning system for RT was carried out using $6 \mathrm{MV}$ photons with Eclipse 2300 CD Varian linear accelerator.

Modeling of Dose Volume Histogram and Isodosis Lines

DICOMan $^{\text {TX }}$ was used to analyze the Dose-Volume Histogram (DVH) and isodose line for all DICOMRT data (Yan et al., 2013). Before the DVH modeling process, the beam's doses in the Treatment Planning System (TPS) were accumulated into one accumulated dose. The accumulated dose was then modeled on a DVH curve to see the dose distribution using the DVH menu. Meanwhile, the isodose line was calculated by multiplying the dose from 5 Gy to $50 \mathrm{~Gy}$.

\section{Biological Model in Plan Optimization}

NCTP values were used to guide clinical decisions, and this modeling used the Lyman Kutcher-Burman (LKB) model (Li et al., 2012; Kutcher \& Burman, 1989). NCTP modeling with the LKB model was carried out on OARs, such as lung, heart, liver, spinal cord, and trachea. NTCP value was assumed to be a sigmoid relationship between carcinoma and Equivalent Uniform Dose (EUD)(Seppenwoolde et al., 2003). The LKB model can be represented 
mathematically by the probit function expressed in equation (1):

$$
\begin{aligned}
\operatorname{NCTP}_{\mathrm{LKB}} & =\frac{1}{\sqrt{2 \pi}} \int_{-\infty}^{\mathrm{t}} \exp \left(\frac{-\mathrm{u}^{2}}{2}\right) \mathrm{du} \\
& =\frac{1}{2}\left[1+\operatorname{erf}\left(\frac{\mathrm{t}}{\sqrt{2}}\right)\right]
\end{aligned}
$$

where $t$ is the upper limit of integrals obtained from the equation (2),

$$
\begin{array}{r}
\mathrm{t}=\frac{\mathrm{gEUD}-\mathrm{TD}_{50}}{\mathrm{mTD}_{50}} \\
\text { gEUD }=\left(\sum_{\mathrm{i}} \frac{\mathrm{v}_{\mathrm{i}}}{\mathrm{v}_{\text {tot }}} \mathrm{d}_{\mathrm{i}}^{\mathrm{a}}\right)^{1 / \mathrm{a}}
\end{array}
$$

The LKB model was generated based on the concept of general uniform dose (gEUD)/EUD $\mathrm{LKB}_{\mathrm{LB}}$, which has been called effective dose, homogeneous dose, and EUD. $\mathrm{d} d_{i}$ refers to the dose and $v_{i}$ is the volume irradiated with dose $d_{i}$. The LKB model consists of three parameters, namely $\mathrm{TD}_{50}, m$, and $\mathrm{a}=1 / \mathrm{n} . \mathrm{TD}_{50}$ represents dose (or relative damaged volume) administered to all organs resulting in a complication of $50 \% \cdot D_{5}$ is the local dose for $50 \%$ local damage. $m$ is the gradient of the LKB model curve (the curve increasing with decreasing $\mathrm{m}$ ) $\mathrm{a}=1 / n$ denotes tissue-specific parameter which explains the volume effect. There are three parameters for the volume effect, including $(\mathrm{a}<-10)$ for tumor, $(a>10)$ for a serial-respond complication, and $(\mathrm{a} \sim 1)$ for parallel-response complication. Then value $n=1$ indicates sensitivity to a volume at the highest dose, while the $\mathrm{n}$ value closer to 1 indicates that the response is due to the average effect across organs (Marks et al., 2010).
The value of NCTP for all risk organs was calculated using open-source CERR software (Deasy et al., 2003) with in-house Matlab software. Therefore, all DICOM-RT data before calculating NCTP with the LKB model had to be converted into the Matlab / CERR format to analyze the NCTP value.

\section{RESULTS AND DISCUSSION}

In this study, three patients with postmastectomy right breast cancer were treated using the IMRT technique with a total dose of $50 \mathrm{~Gy}$ in 25 fractionations. The treatment was analyzed based on dosimetric analysis and biological parameters. The dosimetric analysis is based on the minimum dose and the mean dose values obtained from the DVH accumulation, while the biological parameters correspond to the NTCP value. The IMRT technique based on RTOG 1005 and ICRU 83 is a modulated radiation delivery technique which allows normal, sensitive tissue to obtain a low dose with a fixed target volume to obtain the maximum dose. However, other obstacles in taken into account in planning treatment, especially in breast cancer, because the breast area is close to the heart and lungs, which continuously move so that their position is not always fixed. Therefore, this circumstance requires proper and accurate treatment planning. An optimal treatment planning will have a low-risk toxic effect on organs after radiation exposure.
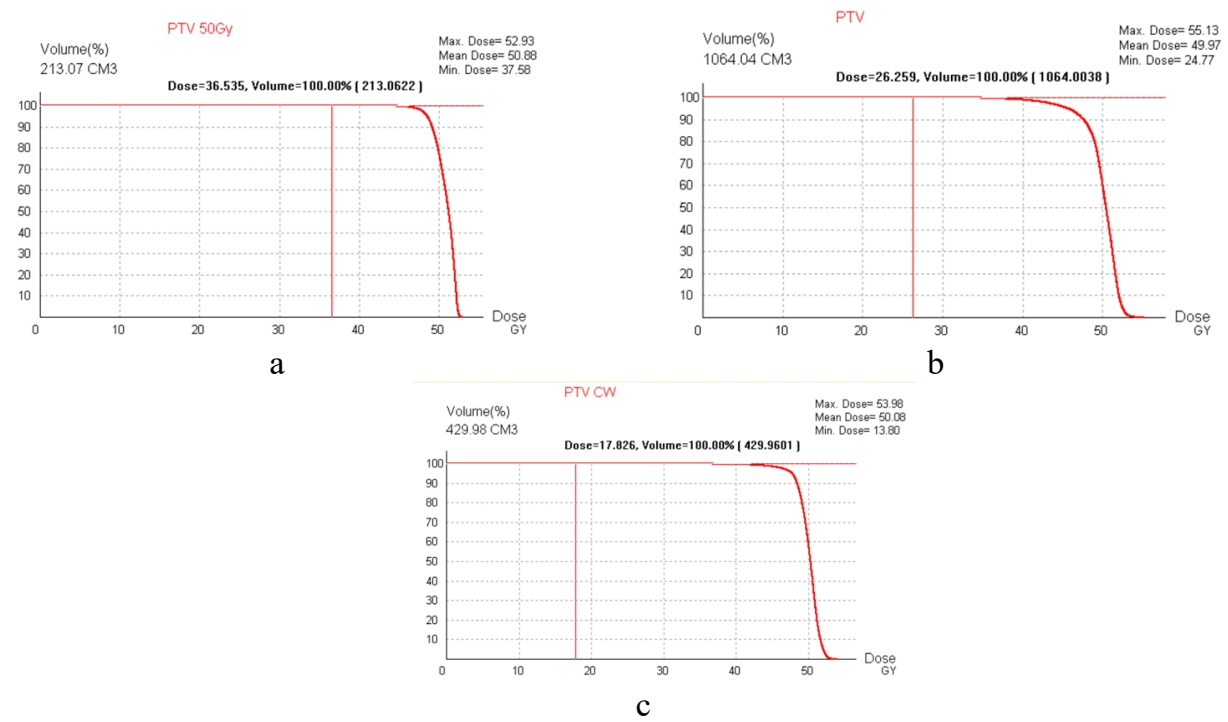

Figure 1. The three types of DVHs in the PTV area produced from the DICOMan ${ }^{\mathrm{TX}}$ software with the sequence of post-mastectomy breast cancer patients are: a. ID 1, b. ID 2 and c. ID 3. 


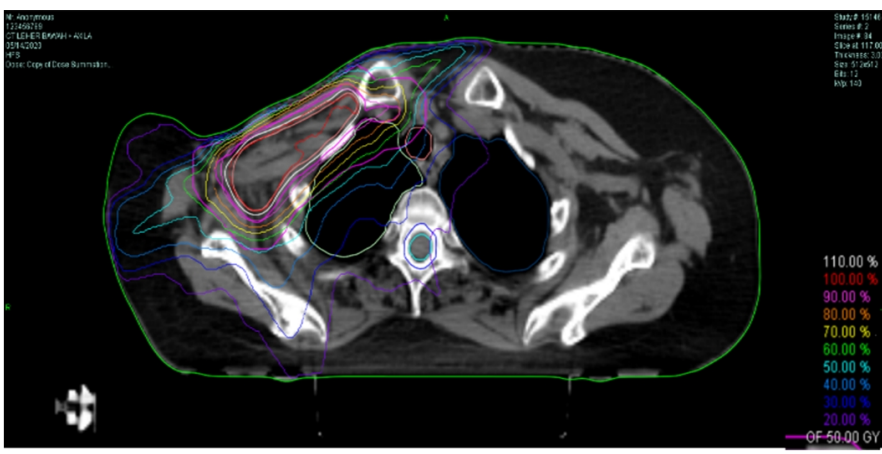

(a)

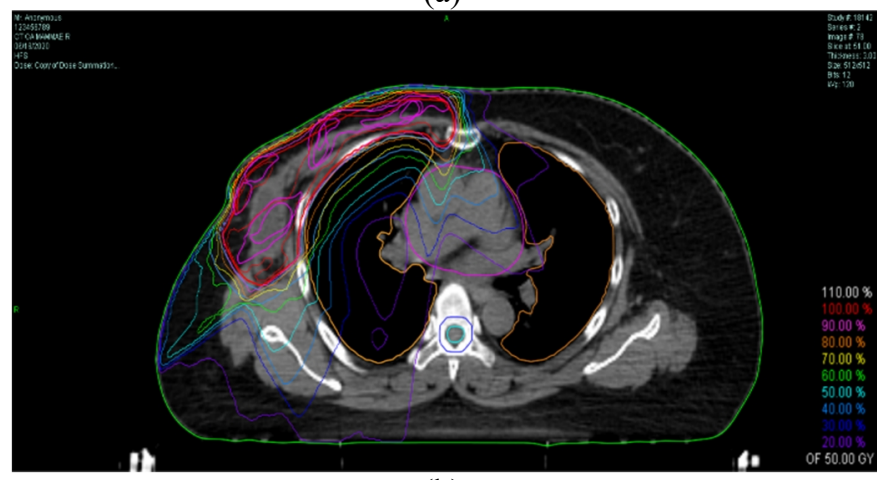

(b)

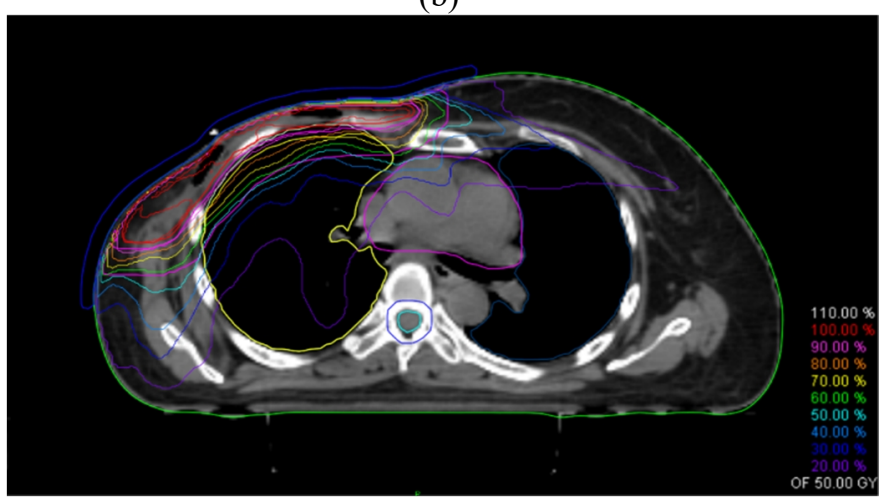

(c)

Figure 2. Results of isodose $2 \mathrm{D}$ using DICOMan ${ }^{\mathrm{TX}}$ software in all 3 post-mastectomy breast cancer patients, a. patient ID 1, b. patient ID 2 and c. patient ID 3

DVH analysis and isodose distribution are complementary parameters for evaluating treatment planning systems based on biological models. Evaluating planning calls for more than the parameters involving mean dose, maximum dose, and minimum dose because these parameters may look similar in several treatment plans but differ in radiobiological results (Lee et al., 2015). The DVH analysis results demonstrate whether the dose distribution in OARs is within tolerance limits or not and whether the target volume is $100 \%$ covered by the dose (Das et al., 2017).

The DVH clinical data shown in Figure 1 were obtained using the DICOM-RT data belonging to MRCCC Siloam Hospital Semanggi, which was processed using the software DICOMan ${ }^{\text {TX }}$. Based on the RTOG 1005 report for the evaluation of PTV, ideally, the dose distribution should cover $\geq 95 \%$ of the total dose given. This means that if the total dose given is $50 \mathrm{~Gy}$, PTV has to obtain $\geq 47.5$ Gy for successful radiation therapy. 
The three patients (ID 1, ID 2, and ID 3) in Table 1 indicatethe dosimetry results as shown by mean dose in the target area (PTV) of 50.88 Gy, 50.49 Gy, and 50.08 Gy, respectively. Based on the mean dose results on PTV, a treatment planning system using the IMRT technique in three patients appear to have achieved the desired dose. Meanwhile, OARS, such as the heart and lungs, have also marked the dose tolerance limits allowed by the RTOG protocol. Based on the RTOG 1005 protocol, the heart can tolerate a maximum mean dose of $\leq 26 \mathrm{~Gy}$, and the lung's limit is $\leq 35 \%$ of the dose, which is equal to $\geq 10$ Gy. Table 2 shows the results of the dose received by the organ at risk closest to the breast/target volumeusing the reference from RTOG 1005. In the heart, it appears that all patients receivedoses below the threshold, meaning that the risk of damage to the heart due to radiation is relatively low. Furthermore, the lung is also the same where the lung's dose is still below the dose threshold. If the dose exceeds the threshold, pneumonitis symptoms in the lungs and pericarditis in the heart may occur.

Table 1. Dose in PTV area based on accumulation DVHs

\begin{tabular}{llllll}
\hline ROI & $\begin{array}{l}\text { Iden- } \\
\text { tities }\end{array}$ & $\begin{array}{l}\text { Min } \\
\text { (Gy) }\end{array}$ & $\begin{array}{l}\text { Mean } \\
\text { (Gy) }\end{array}$ & $\begin{array}{l}\text { Max } \\
\text { (Gy) }\end{array}$ & $\begin{array}{l}\text { Std D } \\
\text { (Gy) }\end{array}$ \\
\hline \multirow{3}{*}{ PTV } & ID 1 & 37.58 & 50.88 & 52.93 & 1.31 \\
& ID 2 & 36.00 & 50.49 & 55.13 & 1.43 \\
& ID 3 & 13.80 & 50.08 & 53.98 & 1.79 \\
\hline
\end{tabular}

Table 2. Tolerance limit in OARs based on the accumulation DVHs

\begin{tabular}{lccc}
\hline \multicolumn{1}{c}{ ROI } & ID 1 & ID 2 & ID 3 \\
\hline $\begin{array}{l}\text { Heart } \\
\text { Meandose } \leq 26 \mathrm{~Gy} \\
\text { Lung Right }\end{array}$ & $0.62 \mathrm{~Gy}$ & $13.9 \mathrm{~Gy}$ & $8.49 \mathrm{~Gy}$ \\
$\mathrm{~V}_{20} \leq 35 \%$ & $11.9 \%$ & $17.67 \%$ & $24.68 \%$ \\
\hline
\end{tabular}

The isodose line was used to explain the dose distribution results on OARs, as shown in Figure 2. Isodose is used to see how wide the dose distribution coverage is in relation to the volume target and organs at risk. The isodose line in Figure 2 is expressed in a relative dose range of $20-100 \%$. For the volume obtained, the highest dose level was 100\% (50 Gy), and the lowest dose level was 20\% (10 Gy).

Based on Figure $2(a, b, c)$, it can be seen thatthe IMRT technique generates an isodose line pattern whichadjusts to the volume target. Figure 2 (a, b, c) also shows that the distribution of the highest dose at 100\% covers all areas of PTV, and the further away from PTV, the dose level decreases so that OARs, such as the heart andlungs, still receive radiation doses within safelimits. Hence, it can be indicated that the dose distribution in the CTV and PTV areas is homogeneous.

Breast cancer from three patients occurred in the right breast area so that the right lung received more radiation than the left lung.Even though this area was exposed to more radiation, it was still below the threshold; this is supported by the results presented in Table 2 . Table 2 shows that the heart is still treated underthe tolerable dose category because the mean dose absorbed by the heart does not exceed $26 \mathrm{~Gy}$. The isodose parameter makes it easier to see the dose homogeneity when it hits the target; this homogeneity will later lead to more possibilities in controlling the tumor, which has fewer side effects on the skin and lungs. Based on the value of DVH and isodose, it can be concluded that treatment planning for the three breast cancer patients is acceptable, but DVH and isodose are still insufficient to evaluate the possible toxicity levels in healthy organs after radiation.

Administering several beams of radiation over a specific time will cause acute toxicity in several organs. Excessive toxicity can cause death in organs. To prevent toxicity, it is necessary to investigate the possibility of complications in normal tissue, analyzed from DVH data. Evaluation based on parameters radiobiological can be obtained through a biological model, i.e., NTCP. 
Table 3. NTCP and EUD values from patient ID 1

\begin{tabular}{|c|c|c|c|c|c|c|}
\hline ID 1 & \multicolumn{6}{|c|}{ NTCP } \\
\hline \multirow{5}{*}{$\begin{array}{l}\text { LKB } \\
\text { Mode }\end{array}$} & ROI & Exponent (a) & $\mathrm{D}_{50}$ & $\mathrm{~m}$ & EUD (Gy) & NTCP (\%) \\
\hline & Lung RT & \multirow{4}{*}{0.67} & \multirow{4}{*}{$\begin{array}{l}21 \\
\text { Gy }\end{array}$} & \multirow{4}{*}{0.59} & 6.5085 & 0.12108 \\
\hline & Heart & & & & 0.46711 & 0.048738 \\
\hline & Spinal Cord & & & & 3.3923 & 0.077641 \\
\hline & Trachea & & & & 15.5305 & 0.32944 \\
\hline \multicolumn{7}{|c|}{ Table 4. NTCP and EUD values from patient ID 2} \\
\hline ID 2 & \multicolumn{6}{|c|}{ NTCP } \\
\hline \multirow{5}{*}{$\begin{array}{l}\text { LKB } \\
\text { Mode }\end{array}$} & ROI & Exponent (a) & $\mathrm{D}_{50}$ & $\mathrm{~m}$ & EUD (Gy) & NTCP (\%) \\
\hline & Lung RT & \multirow{4}{*}{0.67} & & \multirow{4}{*}{0.59} & 14.5549549 & 0.30147 \\
\hline & Heart & & 21 & & 11.3468 & 0.21796 \\
\hline & Spinal Cord & & Gy & & 7.4268 & 0.13665 \\
\hline & Trachea & & & & 13.1897 & 0.26423 \\
\hline
\end{tabular}

Table 5. NTCP and EUD values from patient ID 3

\begin{tabular}{clccccc}
\hline ID 3 & & \multicolumn{5}{c}{ NTCP } \\
\hline & \multicolumn{1}{c}{ ROI } & Exponent (a) & D $_{50}$ & $\mathrm{~m}$ & EUD (Gy) & NTCP (\%) \\
LKB & Lung RT & & & & 13.2353 & 0.26543 \\
Mode & Heart & \multirow{2}{*}{0.67} & 21 & & 6.7903 & 0.12572 \\
& Spinal Cord & & Gy & 0.59 & 2.9037 & 0.072069 \\
& Trachea & & & & 4.4859 & 0.09129 \\
\hline
\end{tabular}

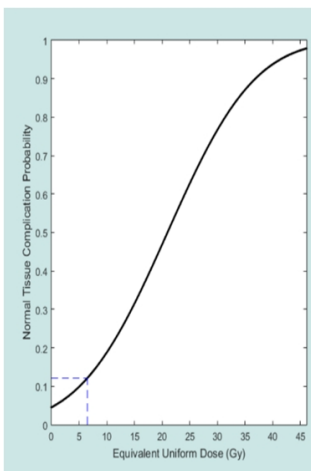

a. Lung

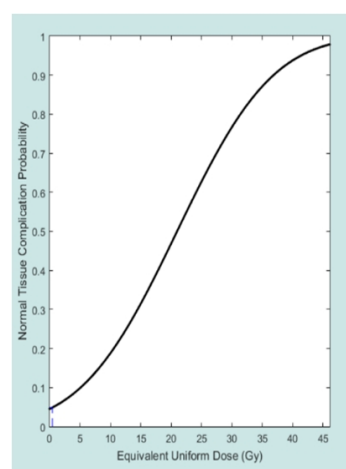

b. Heart

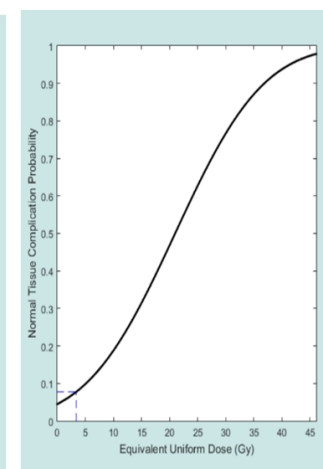

c. Spinal Cord

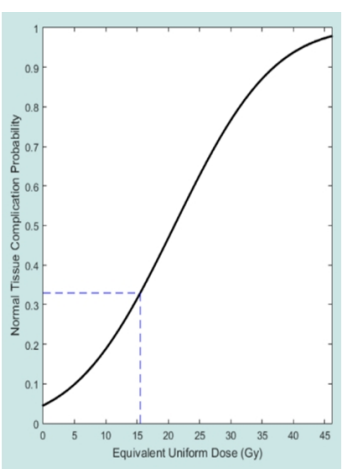

d. Trachea

Figure 3. Sigmoid curve between the percentages of NTCP to the value of the EUD (Gy) in patient ID 1 with a. lung, b. heart, c. spinal cord, d trachea 


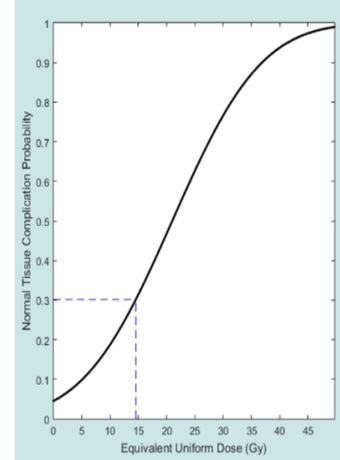

a. Lung

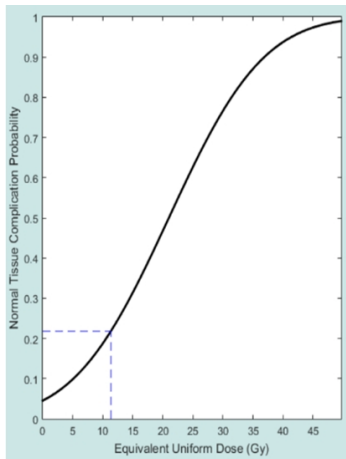

b. Heart

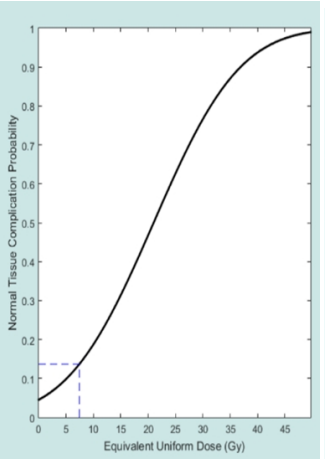

c. Spinal Cord

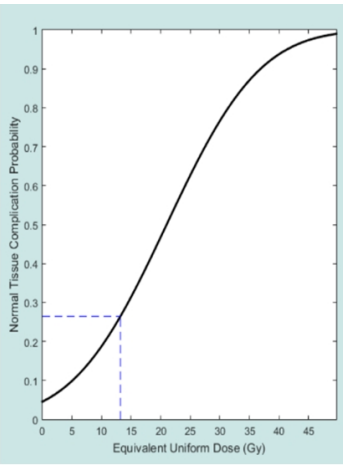

d. Trachea

Figure 4. Sigmoid curve between the percentages of NTCP to the value of the EUD (Gy) in patient ID 2 with a. lung, b. heart, c. spinal cord, d trachea

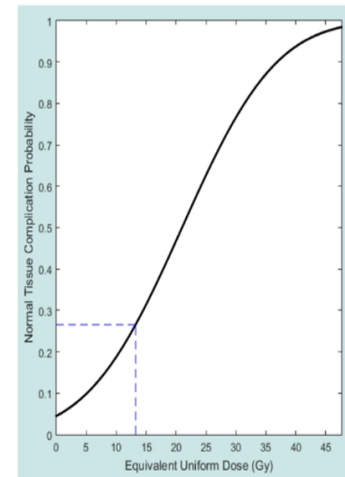

a. Lung

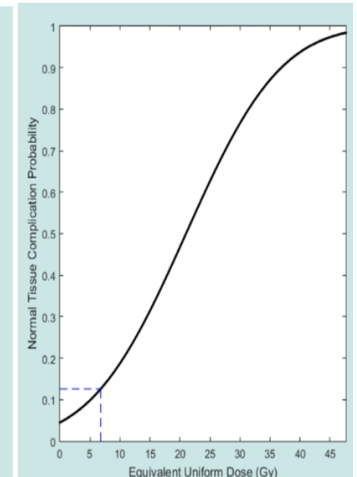

b. Heart

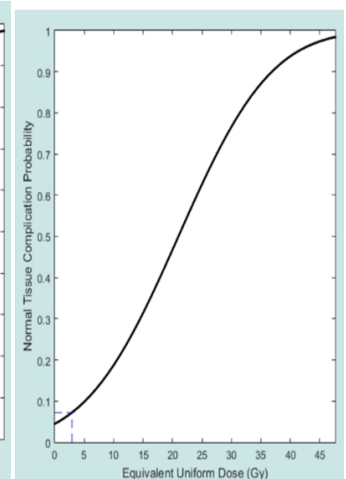

c. Spinal Cord

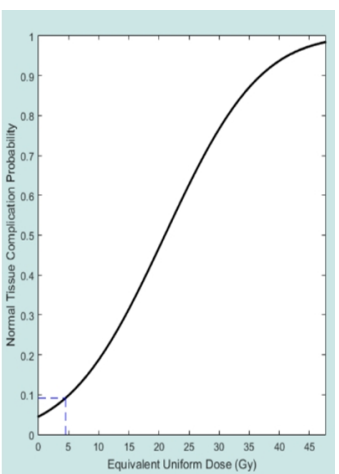

d. Trachea

Figure 5. Sigmoid curve between the percentages of NTCP to the value of the EUD (Gy) in patient ID 3 with a. lung, b. heart, c. spinal cord, d trachea

NTCP is part of the evaluation treatment planning and plays essential rolein clarifying dosimetric information before complex anatomy becomes a risk (Marks et al., 2010). Evaluation of dose distribution at target volume and critical structure is based not only on absorbed dose and volume, but also on radiobiological models such as NTCP. The NTCP model can help improve optimal treatment planning (Tommasino et al., 2017).

NTCP results have been presented in Tables 3, 4, and 5, the data of which are obtained using the DICOMan ${ }^{\text {TX }}$ software. The NTCP value is calculated using LKB model according to formula (1). Tables 3, 4, and 5 present the value of possible complications in normal organs after radiation exposure. Based on the NTCP value, it is known that for normal organs (lung, heart, spinal cord, and trachea) around the target volume, the chance of complications after radiation is minimal because the NTCP value is less than 1 . The
NTCP value results in this study resonate with the study conducted by (Marks et al., 2010), which explains thata complication value equal to 1 denotes possible complication in large parallel organs or large volumes. More details can be seen from the curve between the EUD value against NTCP in Figures 3, 4, and 5. These values show that all OARs for complications are small because the average range of NTCP values for each organ is 0.32 0.077 or less than 1 . The EUD value on the curve also represents something similar to DVH, which means higher EUD value results in an increased probability of complications in healthy organs.

\section{CONCLUSION}

In this study, evaluation of treatment planning performed using the IMRT technique in patients ID 1, 2, and 3 with right breast cancer post-mastectomy has achieved radiotherapy objectives according to ICRU 83 and RTOG 1005. Based on the dosimetric analysis of the 
results of the DVH, isodose, and biological parameters of the NTCP value, the treatment plan made shows a homogeneous dose uniformity in the volume target area. In addition to producing a uniform dose distribution, this evaluation also shows that the NTCP value for each organ is less than 1, which means that the probability of complications after radiation therapy is small.

\section{ACKNOWLEDGEMENTS}

This work was supported by the Institut Teknologi Sepuluh Nopember (ITS), RISTEKBRIN under Penelitian Dasar Unggulan Perguruan Tinggi (PDUPT) (No.1178/PKS/ITS/2020) and MRCCC Siloam Hospital Semanggi in South Jakarta.

\section{REFERENCE}

Abe, O., Abe, R., Enomoto, K., Kikuchi, K., Koyama, H., Masuda, H., Nomura, Y., Sakai, K., Sugimachi, K., Tominaga, T., Uchino, J., Yoshida, M., Haybittle, J. L., Davies, C., Harvey, V. J., Holdaway, T. M., Kay, R. G., Mason, B. H., Forbes, J. F., Caffier, H. 2005. Effects of radiotherapy and of differences in the extent of surgery for early breast cancer on local recurrence and 15-year survival: An overview of the randomised trials. The Lancet, 366(9503), 2087-2106.

American Cancer Society. 2021. Treatment of Breast Cancer Stages I-III. (n.d.). Retrieved January 21, 2021, from https://www.cancer.org/cancer/breastcancer/treatment/treatment-of-breastcancer-by-stage/treatment-of-breast-cancerstages-i-iii.html

Chui, C.-S., Hong, L., Hunt, M., \& McCormick, B. 2002. A simplified intensity modulated radiation therapy technique for the breast. Medical Physics, 29(4), 522-529.

Das, I. J., Andersen, A., Chen, Z. (Jay), Dimofte, A., Glatstein, E., Hoisak, J., Huang, L., Langer, M. P., Lee, C., Pacella, M., Popple, R. A., Rice, R., Smilowitz, J., Sponseller, P., \& Zhu, T. 2017. State of dose prescription and compliance to international standard (ICRU-83) in intensity modulated radiation therapy among academic institutions. Practical Radiation Oncology, 7(2), e145-e155.

Deasy, J. O., Blanco, A. I., \& Clark, V. H. 2003. CERR: A computational environment for radiotherapy research. Medical Physics, 30(5), 979-985.

Early Breast Cancer Trialists' Collaborative Group. 1995. Effects of Radiotherapy and Surgery in Early Breast Cancer - An Overview of the Randomized Trials. New England Journal of Medicine, 333(22), 1444-1456.

Freedman, G. M., Anderson, P. R., Li, J., Eisenberg, D. F., Hanlon, A. L., Wang, L., \& Nicolaou, N. 2006. Intensity modulated radiation therapy (IMRT) decreases acute skin toxicity for women receiving radiation for breast cancer. American Journal of Clinical Oncology: Cancer Clinical Trials, 29(1), 66-70.

Harris, J. R. 2014. Fifty Years of Progress in Radiation Therapy for Breast Cancer. American Society of Clinical Oncology Educational Book, 34, 21-25.

Harsolia, A., Kestin, L., Grills, I., Wallace, M., Jolly, S., Jones, C., Lala, M., Martinez, A., Schell, S., \& Vicini, F. A. 2007. IntensityModulated Radiotherapy Results in Significant Decrease in Clinical Toxicities Compared With Conventional WedgeBased Breast Radiotherapy. International Journal of Radiation Oncology Biology Physics, 68(5), 1375-1380.

Kutcher, G. J., \& Burman, C. 1989. Calculation of complication probability factors for nonuniform normal tissue irradiation: The effective volume method gerald. International Journal of Radiation Oncology, Biology, Physics, 16(6), 16231630.

Lee, S., Cao, Y. J., \& Kim, C. Y. 2015. Physical and Radiobiological Evaluation of Radiotherapy Treatment Plan. In Evolution of Ionizing Radiation Research. InTech. https://doi.org/10.5772/60846

Li, X. A., Alber, M., Deasy, J. O., Jackson, A., Wook, K.-, Jee, K., Marks, L. B., Martel, M. K., Mayo, C., Moiseenko, V., Nahum, A. E., Niemierko, A., Semenenko, V. A., \& Yorke, E. D. 2012. The use and $Q A$ of biologically related models for treatment planning: Short report of the TG-166 of the therapy physics committee of the AAPM a).

Marks, L. B., Yorke, E. D., Jackson, A., Ten Haken, R. K., Constine, L. S., Eisbruch, A., Bentzen, S. M., Nam, J., \& Deasy, J. O. 2010. Use of Normal Tissue Complication Probability Models in the Clinic. International Journal of Radiation 
Oncology Biology Physics, $76(3$ SUPPL.), S10.

Nahum, A. E. (n.d.). CONVERTING DOSE DISTRIBUTIONS INTO TUMOUR CX)NTROL PROBABILITY.

Pyakuryal, A., Myint, W. K., Gopalakrishnan, M., Jang, S., Logemann, J. A., \& Mittal, B. B. 2010. A computational tool for the efficient analysis of dose-volume histograms for radiation therapy treatment plans. Journal of Applied Clinical Medical Physics, 11(1), 137-157.

Ronckers, C. M., Erdmann, C. A., \& Land, C. E. 2005. Radiation and breast cancer: A review of current evidence. In Breast Cancer Research (Vol. 7, Issue 1, pp. 2132). BioMed Central. https://doi.org/10.1186/bcr970

Rudra, S., Al-Hallaq, H. A., Feng, C., Chmura, S. J., \& Hasan, Y. 2014. Effect of RTOG breast/chest wall guidelines on dose-volume histogram parameters *. Journal of Applied Clinical Medical Physics, 15(2), 127-137.

Seppenwoolde, Y., Lebesque, J. V., De Jaeger, K., Belderbos, J. S. A., Boersma, L. J., Schilstra, C., Henning, G. T., Hayman, J. A., Martel, M. K., \& Ten Haken, R. K. 2003. Comparing different NTCP models that predict the incidence of radiation pneumonitis. International Journal of Radiation Oncology Biology Physics, 55(3), 724-735.
Siegel, R. L., Miller, K. D., \& Jemal, A. 2019. Cancer statistics, 2019. CA: A Cancer Journal for Clinicians, 69(1), 7-34.

Supakalin, N., Pesee, M., Thamronganantasakul, K., Promsensa, K., Supaadirek, C., \& Krusun, S. 2018. Comparision of different radiotherapy planning techniques for breast cancer after breast conserving surgery. Asian Pacific Journal of Cancer Prevention, 19(10), 2929-2934.

Tommasino, F., Nahum, A., \& Cella, L. 2017. Increasing the power of tumour control and normal tissue complication probability modelling in radiotherapy: recent trends and current issues. Translational Cancer Research, 6(S5).

Vicini, F. A., Sharpe, M., Kestin, L., Martinez, A., Mitchell, C. K., Wallace, M. F., Matter, R., \& Wong, J. 2002. Optimizing breast cancer treatment efficacy with intensitymodulated radiotherapy. International Journal of Radiation Oncology Biology Physics, 54(5), 1336-1344.

Yan, Y., Mao, W., Ouyang, L., \& Solberg, T. 2013. TH-C-137-01: A Graphical Software Tool for TrueBeam Developer Mode. Medical Physics, 40(6), 532.

Zablotska, L. B., \& Neugut, A. I. 2003. Lung carcinoma after radiation therapy in women treated with lumpectomy or mastectomy for primary breast carcinoma. Cancer, 97(6), 1404-1411. 
